\title{
Medical specialists' basic psychological needs, and motivation for work and lifelong learning: a two-step factor score path analysis
}

Stéphanie M. E. van der Burgt ${ }^{1,5^{*}}$ (D), Rashmi A. Kusurkar ${ }^{1,5}$, Janneke A. Wilschut ${ }^{2,5}$, Sharon L. N. M. Tjin A Tsoi ${ }^{3,5}$, Gerda Croiset ${ }^{1,5}$ and Saskia M. Peerdeman ${ }^{4,5}$

\begin{abstract}
Background: Continuing professional development and lifelong learning are crucial to secure safe and good quality healthcare. Lack of motivation has been found to be among the most important barriers for participation in lifelong learning. This study was conducted to investigate the relationships between medical specialists' work motivation, lifelong learning motivation, autonomy, competence and relatedness satisfaction.

Methods: Self-Determination Theory was used as a theoretical framework for this study. Data were collected through an online survey, that was sent to all $(N=1591)$ medical specialists in four Dutch hospitals. The survey measured background characteristics, autonomy, competence, and relatedness satisfaction, autonomous and controlled work motivation, and lifelong learning motivation. Two step factor path analysis with the method of Croon was used to analyze the data from 193 cases.

Results: Autonomy need satisfaction was positively associated with autonomous work motivation which in turn was positively associated with lifelong learning motivation. Competence need satisfaction and age were negatively associated with controlled work motivation. Competence need satisfaction was also positively related with lifelong learning motivation. No significant nor any hypothesized associations were found for relatedness.
\end{abstract}

Conclusions: Our findings, in line with Self-determination Theory literature, show that autonomy and competence need satisfaction are the important factors as they were positively associated with medical specialists' motivation for work and for lifelong learning.

Keywords: Medical specialists, Motivation, Self determination theory, Two step factor path analysis

\section{Background}

A recent study reported 970 preventable adverse events in Dutch hospitals per year [1]. Globally, the rates of poor performance (which is measured by preventable adverse events) vary from 0.5 to $12 \%$ [2].

\footnotetext{
* Correspondence: s.m.vanderburgt@amsterdamumc.nl

${ }^{1}$ Amsterdam UMC, Vrije Universiteit Amsterdam, Research in Education, VUmc School of Medical Sciences, de Boelelaan 1117, Amsterdam, The Netherlands

${ }^{5}$ LEARN! Research Institute for Learning and Education, Faculty of Psychology and Education, VU University Amsterdam, Amsterdam, The Netherlands Full list of author information is available at the end of the article
}

These poor performance rates lead to reduced quality of care and patient safety. Through professional development, i.e., lifelong learning, medical specialists maintain their professional competence and are able to keep track of and respond to advancing knowledge in their field [3, 4, 9-12]. Continuing professional development (CPD) and lifelong learning as part of $\mathrm{CPD}$ are crucial to secure high quality healthcare, patient safety, and societal trust in the healthcare system [3-5]. While learning and development opportunities are energizing factors for practicing

(c) The Author(s). 2019 Open Access This article is distributed under the terms of the Creative Commons Attribution 4.0 International License (http://creativecommons.org/licenses/by/4.0/), which permits unrestricted use, distribution, and 
healthcare professionals, lack of motivation, time, and funding constitute the most significant barriers for participation in CPD and lifelong learning [5-8]. Since lack of motivation is mentioned as a barrier, an insight into the motivation mechanism of medical specialists would be useful as this makes it possible to enable the development of an optimal environment for specialists to work in, as well as to keep medical specialists participating in lifelong learning. However, to our knowledge, little is known about the motivation of medical specialists for medical practice (work motivation) and for lifelong learning/CPD in particular. Accordingly, the focus of this study is on the work motivation of medical practice and lifelong learning of medical specialists.

The aim of this study is to investigate the score on autonomous motivation (AM), controlled motivation (CM) and lifelong learning motivation as well as the relationship between work motivation (AM and $\mathrm{CM}$ ), motivation for lifelong learning and the satisfaction of the three basic psychological needs: autonomy, competence and relatedness. The proposed model for this study is illustrated in Fig. 1. The three basic needs and autonomous and controlled motivation are not considered to be independent. Thus, they are often found to be related. The hypotheses that were specified based on the literature are as follows:

1. Autonomy, competence, and relatedness are positively associated with medical specialists' AM for work and lifelong learning motivation and negatively associated with medical specialists' CM for work.

2. AM for work is positively associated with medical specialists' lifelong learning motivation.

3. CM for work is negatively associated with medical specialists' lifelong learning motivation.

We used the Self-determination theory (SDT) of Deci and Ryan as the framework for the current study [13-17]. SDT classifies motivation on a dynamic continuum and emphasizes the importance of the quality of the motivation. This sets it apart from other theories which put more emphasis on the quantity of the motivation. Several different states of quality of motivation are aligned along the continuum: amotivated, external regulation, introjected regulation, identified regulation, integrated regulation, and intrinsic motivation. Of these, external and introjected regulation together form CM. Identified and integrated regulation and intrinsic motivation together form AM. According to SDT AM comes from within the individual out of interest for and value of the task itself, and is a facilitator and stimulator of deep-level learning and academic performance; it also leads to improved wellbeing, resilience, and patient safety [13-17]. CM is feeling pressured or coerced by external factors or from within and is associated with less desirable outcomes like procrastination and surface-level learning [13-17].

Additionally, within SDT, three basic psychological needs are distinguished: perceived autonomy (experiencing behavior as choiceful and self-endorsed), perceived competence (experiencing behavior as masterful), and relatedness (feeling mutually connected with peers and important others) [13-17]. Perceived competence in this study is the person's perception of their own competence, rather than professional competence which is generally measured by others such as supervisors or peers. When these basic needs are satisfied this promotes a person's psychological growth, healthy functioning, and AM. When these needs are frustrated or thwarted this contributes to malfunction, reduced energy and wellbeing, and CM [14, 19-21].

\section{Methods}

Setting and sample

A quantitative study was conducted in an academic hospital (VU University Medical Center in

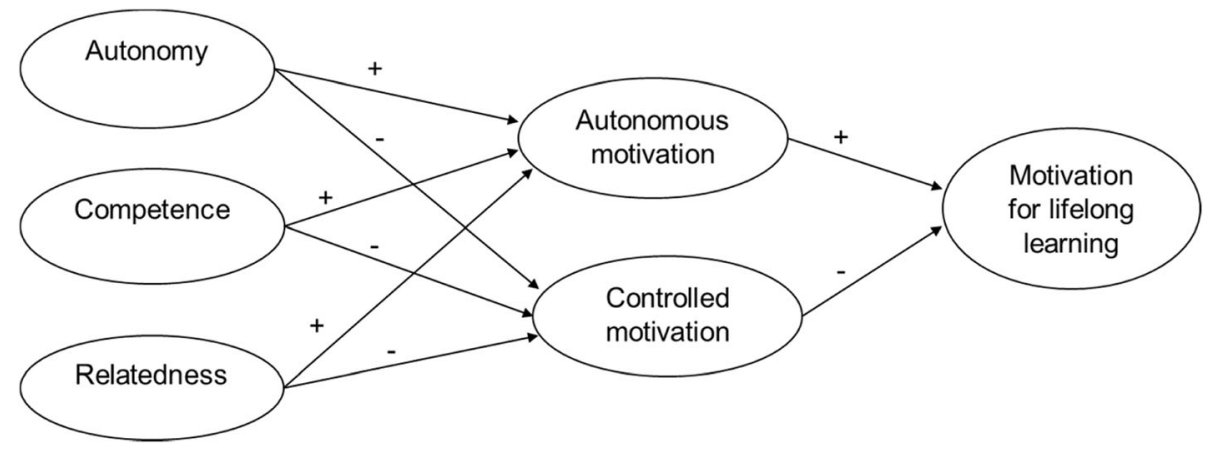

Fig. 1 Hypothesized model with all latent variables 
Amsterdam), a large merged medical center (Noordwestgroep Alkmaar and OLVG Amsterdam), and two affiliated hospitals (Westfriesgasthuis Hoorn and Rode Kruis Ziekenhuis Beverwijk). An online questionnaire was sent to all the medical specialists working in these hospitals. In this study, our definition of a medical specialist is a physician who has completed specialty training.

\section{Data collection}

The online questionnaire included standardized validated scales measuring work motivation (with subscales for $\mathrm{AM}$ and $\mathrm{CM}$ ), the motivation for lifelong learning, and the basic psychological needs of autonomy, competence and relatedness. Additionally, we included the following questions about the background characteristics: sex, age, type of specialty, type of hospital that they work in, and number of years of experience as a medical specialist. The validated scales were translated from English into Dutch by two researchers. They were then back translated by two other researchers to ensure the appropriate Dutch translation [22].

\section{Measures}

The 19-item multidimensional work motivation scale (MWMS) [23] was used to measure the work motivation of the medical specialists. This scale could be divided into AM and CM for work. The stem of the scale is "Why do you or would you put efforts into your current job?" with items like; e.g., "Because I personally consider it important to put efforts into this job." Responses were made on a seven point Likert scale. All responses to the questions were added together, with the higher scores indicating a higher level of motivation. For this scale Cronbach's alpha was 0.83 for AM and 0.79 for CM.

The 14-item revised Jefferson Scale of Physician Lifelong Learning (JeffSPLL) [24] was used to measure the medical specialists' motivation for lifelong learning. The stem of the scale is "Please indicate the extent of your agreement with each of the following statements by circling the appropriate number" with items like: "I believe that I would fall behind if I stopped learning about new developments in my profession." Responses were made on a fourpoint Likert scale and were also added together. Here, higher scores also indicate a greater orientation and motivation toward lifelong learning. For this scale Cronbach's alpha was 0.85 .

The Basic Psychological Needs at Work Scale (BPNWS) [25] assessed the perceived autonomy and competence at work of medical specialists. Both subcategories included eight items, e.g.: "I feel my choices in my job express who I really am" (for autonomy) and "When I am at work, I feel competent to achieve my goals" (for competence). Responses were made on a seven point Likert scale. The Cronbach's alpha was 0.71 for autonomy and 0.78 for competence. Relatedness of medical specialists toward their colleagues was measured with the TEAM Climate Inventory scale (TCI) [26], which included 12 items, e.g.: "People feel understood and accepted by each other." Responses were made on a five point Likert scale. For this scale, the Cronbach's alpha was 0.92 .

\section{Analysis}

Descriptive statistics were used to assess demographic data such as gender and years of experience. Data were checked for normality distribution and the assumption of a normal multivariate distribution was met. In order to investigate reliability and to get information on validity we computed Cronbach's alphas. Pearson's correlations of all variables were also computed. These analyses were performed using the SPSS 22.0 software program. We then performed a factor score path analysis with Mplus 7.0, using the method of Croon [27-30], to investigate the hypothesized association shown in Fig. 1. To overcome sample size issues, the two step factor score regression (FSR) approach is often used instead of SEM analysis. In this approach the first step is to perform a factor analysis and to calculate factor scores for each latent variable. These factor scores are estimates for the true latent variable scores. In the second step, the factor scores are used in a linear regression, as if they were the true latent variable scores. However, the use of factor scores results in biased estimates of the regression parameters. Croon developed a FSR method that corrects for this bias by using an estimation of the variances and covariances of the true latent variable scores instead of the factor scores [27-29]. This is the method that we have used. Additionally, because our hypothesized model includes mediational relationships we performed a series of linear regression analyses/path analysis. The method can be summarized as follows:

1. Perform factor analysis for all latent variables separately and calculate their respective factor scores.

2. Calculate the variance-covariance matrix of the factor scores.

3. Estimate the true variances and covariances for all elements in this variance-covariance matrix. 
4. Perform a path analysis using estimated variances and covariances as the input covariance matrix for the model.

Modelfit was assessed using the following criteria: a chi-square, a $p$-value of $>0.05$, a comparative fit index (CFI) of $>0.95$, a Tucker Lewis index (TCI) $>$ 0.95 and a root mean square error approximation (RMSEA) of $<0.06$.

\section{Results}

Out of 1591 medical specialists, a total of 193 specialists from 30 different specialties completed our questionnaire, resulting in a response rate of $12.1 \%$. According to the power analysis that we conducted we needed a minimum of 180 cases. The a priori power analysis was conducted using two tailed tests with a medium effect size of 0.3 , an alpha error probability of 0.05 and a power of 0.95 .

Of the specialists, $85(43.8 \%)$ were male and 108 (56.2\%) were female, the mean age was 49 years, and $56.2 \%$ of the specialists worked in a non-academic hospital. Table 1 reports the participants' mean scores on the different types of work motivation and the basic psychological needs satisfaction. Table 1 also shows the division of the specialties into three groups; surgical, non-surgical and supportive, which are based on the division that is used by NIVEL, the National institute for health research in the Netherlands [31]. NIVEL uses a division of six groups: First-line curative care (i.e. general practitioner), Public healthcare (i.e. occupational physician), Psychiatry (except psychiatrist working at a hospital), Surgical (all specialties that work in the operating theatre), Non-surgical (i.e. dermatologist,

Table 1 Mean scores on AM (autonomous work motivation), CM (controlled work motivation), lifelong learning motivation, and basic psychological need satisfaction

\begin{tabular}{|c|c|c|c|c|c|c|c|}
\hline & $N(\%)$ & $\mathrm{AM}$ & $C M$ & $\begin{array}{l}\text { Lifelong learning } \\
\text { motivation }\end{array}$ & $\begin{array}{l}\text { Autonomy } \\
\text { satisfaction }\end{array}$ & $\begin{array}{l}\text { Competence } \\
\text { satisfaction }\end{array}$ & $\begin{array}{l}\text { Relatedness } \\
\text { satisfaction }\end{array}$ \\
\hline \multicolumn{8}{|l|}{ Gender } \\
\hline Male & $84(43.5)$ & 5.66 & 3.28 & 3.21 & 4.34 & 3.85 & 3.84 \\
\hline \multirow[t]{2}{*}{ Female } & $\begin{array}{l}108 \\
(56.5)\end{array}$ & 5.87 & 3.35 & 3.11 & 4.40 & 3.82 & 3.67 \\
\hline & & ns & ns & ns & ns & ns & ns \\
\hline \multicolumn{8}{|l|}{ Age } \\
\hline$<50$ years & $\begin{array}{l}106 \\
(54.9)\end{array}$ & 5.89 & 3.41 & 3.11 & 4.36 & 3.82 & 3.79 \\
\hline \multirow[t]{2}{*}{$>50$ years } & $87(45.1)$ & 5.66 & 3.20 & 3.21 & 4.38 & 3.84 & 3.72 \\
\hline & & $\begin{array}{l}p< \\
0.05\end{array}$ & ns & ns & ns & ns & ns \\
\hline \multicolumn{8}{|c|}{ Years of experience } \\
\hline$<15$ years & $110(57)$ & 5.84 & 3.43 & 3.10 & 4.36 & 3.83 & 3.75 \\
\hline \multirow[t]{2}{*}{$>15$ years } & $83(43)$ & 5.71 & 3.17 & 3.22 & 4.37 & 3.87 & 3.76 \\
\hline & & ns & $\begin{array}{l}p< \\
0.05\end{array}$ & $p<0.05$ & ns & ns & ns \\
\hline \multicolumn{8}{|l|}{ Type of hospital $^{a}$} \\
\hline Academic & 75 (38.9) & 5.84 & 3.30 & 3.23 & 4.45 & 3.89 & 3.64 \\
\hline \multirow[t]{2}{*}{$\begin{array}{l}\text { Non- } \\
\text { academic }\end{array}$} & $\begin{array}{l}108 \\
(56.1)\end{array}$ & 5.81 & 3.38 & 3.09 & 4.43 & 3.80 & 3.82 \\
\hline & & ns & ns & $p<0.05$ & ns & ns & ns \\
\hline \multicolumn{8}{|c|}{ Type of Specialty ${ }^{a}$} \\
\hline Surgical & 49 (25.9) & 5.89 & 3.21 & 3.17 & 4.26 & 3.82 & 3.90 \\
\hline Non-surgical & $95(50.3)$ & 5.76 & 3.39 & 3.15 & 4.38 & 3.83 & 3.69 \\
\hline \multirow[t]{2}{*}{ Supportive } & 45 (23.8) & 5.68 & 3.22 & 3.13 & 4.43 & 3.78 & 3.74 \\
\hline & & ns & ns & ns & ns & ns & ns \\
\hline
\end{tabular}

Mean scores of AM and CM are based on a seven point Likert scale, lifelong learning motivation on a four point Likert scale and basic psychological needs on a five point Likert scale.

a Less than 193 cases as not all participants answered the questions 
Table 2 Pearson correlations of autonomous, controlled and lifelong learning motivation; and autonomy, competence and relatedness satisfaction

\begin{tabular}{|c|c|c|c|c|c|c|}
\hline & $\begin{array}{l}\text { AM (Autonomous work } \\
\text { motivation }\end{array}$ & $\begin{array}{l}\text { CM (controlled work } \\
\text { motivation) }\end{array}$ & $\begin{array}{l}\text { Lifelong learning } \\
\text { motivation }\end{array}$ & $\begin{array}{l}\text { Autonomy } \\
\text { satisfaction }\end{array}$ & $\begin{array}{l}\text { Competence } \\
\text { satisfaction }\end{array}$ & $\begin{array}{l}\text { Relatedness } \\
\text { satisfaction }\end{array}$ \\
\hline $\begin{array}{l}\text { AM (Autonomous Work } \\
\text { Motivation) }\end{array}$ & 1 & & & & & \\
\hline $\begin{array}{l}\text { CM (Controlled Work } \\
\text { Motivation) }\end{array}$ & -0.005 & 1 & & & & \\
\hline $\begin{array}{l}\text { lifelong learning } \\
\text { motivation }\end{array}$ & $0.342^{*}$ & -0.042 & 1 & & & \\
\hline Autonomy satisfaction & 0.107 & $0.154^{*}$ & 0.012 & 1 & & \\
\hline Competence satisfaction & 0.115 & $0.220^{*}$ & 0.125 & 0.109 & 1 & \\
\hline Relatedness satisfaction & 0.135 & -0.027 & 0.057 & -0.051 & 0.070 & 1 \\
\hline
\end{tabular}

${ }^{*} p<0.05$

cardiologist) and Supportive (i.e. anesthesiologist, pathologist). However, the groups first-line care, public healthcare and psychiatry were not applicable to our study as these specialists are not working in hospitals. Missing data was handled per variable because of the already small sample size. Some variables did not have any missing data and therefore have the complete number of 193 participants with 183 as smallest $\mathrm{N}$ on the variable type of hospital. Other variables did have missing data and therefore have a total number of participants that is lower than 193. Differences between mean scores were tested for significance by using a t-test. For differences between type of specialty ANOVA was used.

Table 1: Mean scores on AM (autonomous work motivation), CM (controlled work motivation), lifelong learning motivation, and basic psychological need satisfaction.

Before conducting the factor score path analysis, Pearson correlations were calculated (Table 2). Three significant Pearson correlations were found. AM and motivation for lifelong learning were significantly positively correlated. Autonomy and competence need satisfaction were both significantly positively correlated with CM.

Following the four steps of the FSR with the Croon method we first performed a factor analysis for all latent variables and calculated their factor scores. Factor scores were calculated using the regression predictor. Factor loadings are presented in the Table 4 in Appendix, followed by Table 5 in Appendix that shows the goodness of fit for all variables. Because all scales have been validated thoroughly before and the Cronbach's alphas were all quite high the model fit for all variables was good. Secondly we calculated the variance-covariance matrix for all factor scores. For the third step we estimated the true variances and covariances for all elements in the variance-covariance matrix. The results are shown in Table 3.

As a final step we performed a path analysis using estimated variances and covariances as the input covariance matrix for the model. This provided us the following fit indices of our hypothesized model:

Table 3 True variances and covariances for all elements

\begin{tabular}{|c|c|c|c|c|c|c|}
\hline & $\begin{array}{l}\text { AM (Autonomous } \\
\text { Motivation) }\end{array}$ & $\begin{array}{l}\text { CM (Controlled } \\
\text { motivation) }\end{array}$ & $\begin{array}{l}\text { Lifelong learning } \\
\text { motivation }\end{array}$ & $\begin{array}{l}\text { Autonomy } \\
\text { satisfaction }\end{array}$ & $\begin{array}{l}\text { Competence } \\
\text { satisfaction }\end{array}$ & $\begin{array}{l}\text { Relatedness } \\
\text { satisfaction }\end{array}$ \\
\hline $\begin{array}{l}\text { AM (Autonomous } \\
\text { Motivation) }\end{array}$ & 0.559 & & & & & \\
\hline $\begin{array}{l}\text { CM (Controlled } \\
\text { motivation) }\end{array}$ & -0.003 & 0.665 & & & & \\
\hline $\begin{array}{l}\text { Lifelong learning } \\
\text { motivation }\end{array}$ & 0.108 & -0.012 & 0.132 & & & \\
\hline Autonomy satisfaction & 0.035 & 0.059 & 0.005 & 0.224 & & \\
\hline $\begin{array}{l}\text { Competence } \\
\text { satisfaction }\end{array}$ & 0.032 & 0.067 & 0.018 & 0.020 & 0.142 & \\
\hline $\begin{array}{l}\text { Relatedness } \\
\text { satisfaction }\end{array}$ & 0.052 & -0.016 & 0.020 & -0.012 & 0.016 & 0.405 \\
\hline
\end{tabular}




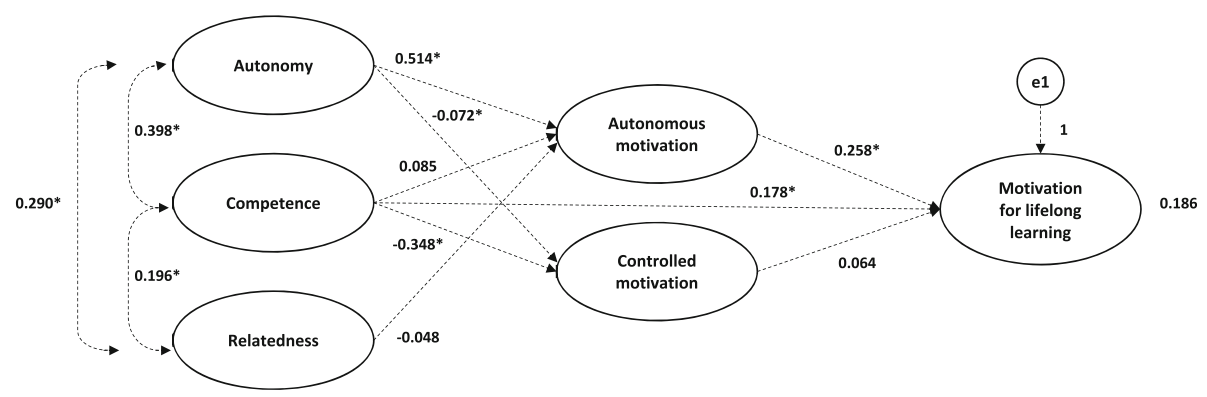

Fig. 2 Final model of the structural relations identified. ${ }^{*} p<0.05$

$\mathrm{X}^{2}=0.463(\mathrm{df}=4, p=0.977), \mathrm{CFI}=1, \mathrm{TFI}=1$, and RMSEA $=0.00$. The CFI and TFI being 1 shows that this model is overfitting, it is more complex than it should be. Therefore, we re-specified and assessed the model based on statistical output and theoretical relevance. Figure 2 depicts our final model with a good model fit following from the fit indices: $\mathrm{X}^{2}=$ $23.681 \quad(\mathrm{df}=16, \quad p=0.097), \quad \mathrm{CFI}=0.950, \quad$ and RMSEA $=0.05$.

Perceived autonomy was positively associated with AM for work which in turn was positively associated with lifelong learning motivation (Fig. 2). Competence was negatively associated with CM for work. Competence was also directly positively associated with lifelong learning motivation. Experiencing autonomy and competence contributes to medical specialists being more motivated for lifelong learning. No significant relationship was found for relatedness.

\section{Discussion}

The aim of this study was to investigate the relationship between work motivation (AM and CM), motivation for lifelong learning, and the three basic psychological needs of Self-determination Theory.

We expected autonomy, competence, and relatedness satisfaction to be positively associated with medical specialists' AM for work and motivation for lifelong learning, and to be negatively associated with medical specialists' CM for work. We did observe a positive association between autonomy satisfaction and AM and a negative association between competence satisfaction and CM. Furthermore, competence satisfaction had a direct significant positive association with specialists' motivation for lifelong learning. However, no significant associations for relatedness satisfaction were found, which could suggest that relatedness is difficult to measure quantitatively. Another explanation could be that autonomy and competence are more important than relatedness for work and lifelong learning motivation. A third explanation can be that relatedness was measured with the TCI scale and the other two basic needs were measured with BNWS.

Second, we expected AM for work to be positively associated with medical specialists' lifelong learning motivation. This is indeed the case in the present study, thus in line with SDT $[13-15,18]$. When a specialist has a higher AM for work, it stimulates their daily task-related motivation. One such task is CPD, i.e., lifelong learning. If a medical specialist likes their work, they are more likely to continue learning about it. AM also functions as a mediator for the association of autonomy with the motivation for lifelong learning.

Third, the expectation was that CM for work would be negatively associated with medical specialists' motivation for lifelong learning. However, no significant association between $\mathrm{CM}$ and lifelong learning motivation was found. Although this is not in line with SDT, another study on motivation for lifelong learning among pharmacists had the same results [32]. One potential explanation is that other predictors (autonomy, competence and AM) are so strongly associated with the motivation for lifelong learning that $\mathrm{CM}$ for work has no significant role. The possibility of the basic psychological needs satisfaction as predictors for learning outcomes (in this case, lifelong learning) is supported by earlier studies that were conducted in different context with workers, nurses, pharmaclists, and across different cultures within SDT [21, 32, 33].

We noted a few significant findings from the results of the background characteristics on the different types of motivation. The type of hospital had a significant negative association with the motivation for lifelong learning. This indicates that working in a non-academic hospital is connected to a lower motivation for lifelong learning than working in an academic hospital. One explanation might be that the combination of patient care, research, and education in an academic setting challenges medical 
specialists' knowledge and competence in a more autonomous way. It is also possible that working in a non-academic hospital obligates medical specialists to spend time on production and funding, which takes away time and joy from other tasks/ factors like patient care, which actually enhance AM. However, medical specialists who choose to work in an academic hospital could already be more autonomously motivated. Medical specialists with more years of experience score lower on CM for work. These results are also in line with research that showed that pharmacists working for more than 10 years are found in more autonomous motivation profiles [32]. Volkening et al. demonstrated that AM significantly increased with age [34]; however, older medical specialists do not score higher on AM for work. One explanation could be that as medical specialists gain more experience, the interventions become more routine and less challenging. This could take away from feeling competent and in turn from being autonomously motivated.

Autonomy and competence satisfaction seem to be the most important for basic needs for lifelong learning motivation of medical specialists. However, autonomy is currently being significantly thwarted in healthcare systems. Rules and regulations are becoming increasingly dominant in healthcare and are likely to decrease autonomy among specialists and make specialists feel more like administrative employees than physicians [36]. Because of the continuous and rapid technological and social developments, there could be a reduction in experienced competence and therefore in AM for work and lifelong learning motivation.

To support medical specialists' participation in lifelong learning, measures need to be taken to reinstate their sense of autonomy and competence. When work contexts support the basic needs satisfaction this is perceived to not only stimulate optimal motivation, functioning, and wellbeing among employees, but also has benefits for the organization [37]. This could include empowering specialists to be autonomous in their time planning, develop a customized professional development route, and provide for the specialists to devote most of their time to patient care and teaching, from which they derive most of their inspiration [35, 36]. The findings suggest more tailored lifelong learning pathways where specialists can decide themselves whether to and how to fulfill their individual motivational needs for AM for work and lifelong learning. Diverse options for learning formats can be offered, such as hands-on courses, e-learning, workshops and so on, which would enable specialists to make choices in their learning.

\section{Limitations and future research}

The work motivation scale we used has been validated in many professions; however, it has not been used among healthcare professionals. Thus, further validation of this scale among healthcare professionals is necessary. While the sample in this study is small and the response rate low we had sufficient power to detect significant differences. It is common knowledge that medical specialists are sent an overwhelming amount of questionnaires, and they already have too little time to do their daily job. Thus, it is possible that it takes motivated specialists to participate in the questionnaires in the first place. If this is the case, then it might be that the level of motivation can be overestimated in this study. Considering the context, the response rate is reasonable for this population and above the minimum number according to the power analysis.

Moreover, the questionnaires we used consisted of self-assessment scales. Respondents tend to overestimate themselves when filling out these scales. This could mean that the results provided an overestimation of the level of motivation. If this is indeed the case, the need to reinstate medical specialists' perceived autonomy and competence is even more urgent.

For the measurement of years of experience, we assumed that specialists gain competence as they build their experience (measured by longevity). It seems logical to assume that there is a positive correlation between competence and experience. However, in many settings, especially those where physicians take on nonclinical responsibilities, such as teaching, administration, and research, the level of (patient) experience is reduced by these other activities. For future research, other measures of experience need to be considered, such as the number of procedures conducted or the number of patients seen, rather than longevity.

Although SDT is a universal theory that has been validated in many life domains and across cultures, not much is known about the motivation of medical specialists. More research in other healthcare contexts is necessary to determine the generalizability of our findings. Future research on relatedness among medical specialists, mainly qualitative, is needed to determine how this basic need can be fulfilled. Moreover, measuring relatedness with a different scale (TCI) than the one for other basic needs might be a limitation of this study.

\section{Conclusion}

Our findings, in line with the SDT literature, show that autonomy and competence satisfaction are the most important factors for medical specialists' motivation for work and lifelong learning. These factors should be taken into account when designing interventions to optimize specialists' motivation. 


\section{Appendix}

Table 4 CFA factor loadings on all variables

\begin{tabular}{|c|c|c|c|c|c|c|}
\hline Item & $\begin{array}{l}\text { Autonomous } \\
\text { motivation }\end{array}$ & $\begin{array}{l}\text { Controlled } \\
\text { motivation }\end{array}$ & $\begin{array}{l}\text { Lifelong learning } \\
\text { motivation }\end{array}$ & $\begin{array}{l}\text { Autonomy } \\
\text { satisfaction }\end{array}$ & $\begin{array}{l}\text { Competence } \\
\text { satisfaction }\end{array}$ & $\begin{array}{l}\text { Relatedness } \\
\text { satisfaction }\end{array}$ \\
\hline WM2 & & 1.000 & & & & \\
\hline WM3 & & 0.620 & & & & \\
\hline WM4 & & 0.996 & & & & \\
\hline WM5 & 1.000 & & & & & \\
\hline WM6 & 0.965 & & & & & \\
\hline WM8 & & 0.939 & & & & \\
\hline WM9 & & 1.066 & & & & \\
\hline WM10 & & 0.808 & & & & \\
\hline WM11 & 0.872 & & & & & \\
\hline WM12 & 1.370 & & & & & \\
\hline WM14 & & 0.978 & & & & \\
\hline WM15 & & 0.913 & & & & \\
\hline WM16 & & 0.961 & & & & \\
\hline WM17 & 1.177 & & & & & \\
\hline WM18 & 1.421 & & & & & \\
\hline WM19 & & 0.605 & & & & \\
\hline MLLL1 & & & 1.000 & & & \\
\hline MLLL2 & & & 0.641 & & & \\
\hline MLLL3 & & & 1.383 & & & \\
\hline MLLL4 & & & 0.894 & & & \\
\hline MLLL5 & & & 1.431 & & & \\
\hline MLLL6 & & & 1.368 & & & \\
\hline MLLL7 & & & 0.773 & & & \\
\hline MLLL8 & & & 0.900 & & & \\
\hline MLLL9 & & & 0.991 & & & \\
\hline MLLL10 & & & 1.623 & & & \\
\hline MLLL11 & & & 1.500 & & & \\
\hline MLLL12 & & & 1.263 & & & \\
\hline MLLL13 & & & 1.647 & & & \\
\hline MLLL14 & & & 0.783 & & & \\
\hline AUT1 & & & & 1.000 & & \\
\hline AUT2 & & & & 0.910 & & \\
\hline AUT3 & & & & 0.875 & & \\
\hline AUT4 & & & & 1.050 & & \\
\hline AUT5 & & & & 0.954 & & \\
\hline AUT6 & & & & 0.684 & & \\
\hline AUT7 & & & & 0.733 & & \\
\hline AUT8 & & & & 0.905 & & \\
\hline COMP1 & & & & & 1.000 & \\
\hline COMP2 & & & & & 1.504 & \\
\hline COMP3 & & & & & 1.039 & \\
\hline
\end{tabular}


Table 4 CFA factor loadings on all variables (Continued)

\begin{tabular}{|c|c|c|c|c|c|c|}
\hline Item & $\begin{array}{l}\text { Autonomous } \\
\text { motivation }\end{array}$ & $\begin{array}{l}\text { Controlled } \\
\text { motivation }\end{array}$ & $\begin{array}{l}\text { Lifelong learning } \\
\text { motivation }\end{array}$ & $\begin{array}{l}\text { Autonomy } \\
\text { satisfaction }\end{array}$ & $\begin{array}{l}\text { Competence } \\
\text { satisfaction }\end{array}$ & $\begin{array}{l}\text { Relatedness } \\
\text { satisfaction }\end{array}$ \\
\hline COMP4 & & & & & 1.385 & \\
\hline COMP5 & & & & & 1.012 & \\
\hline COMP6 & & & & & 1.847 & \\
\hline COMP7 & & & & & 0.950 & \\
\hline COMP8 & & & & & 1.052 & \\
\hline REL 1 & & & & & & 1.000 \\
\hline REL2 & & & & & & 0.905 \\
\hline REL3 & & & & & & 1.042 \\
\hline REL4 & & & & & & 0.821 \\
\hline REL5 & & & & & & 0.889 \\
\hline REL6 & & & & & & 0.726 \\
\hline REL7 & & & & & & 0.931 \\
\hline REL8 & & & & & & 0.469 \\
\hline REL9 & & & & & & 1.025 \\
\hline REL 10 & & & & & & 0.999 \\
\hline REL11 & & & & & & 1.098 \\
\hline REL12 & & & & & & 1.198 \\
\hline
\end{tabular}

WM = work motivation. WM1, WM7 and WM13 are the items for amotivation, which are left out because we do not include amotivation in our analysis. MLLL = lifelong learning motivation, AUT = Autonomy, COMP = Competence, $\mathrm{REL}=$ Relatedness

Table 5 Goodness of fit indices for all variables

\begin{tabular}{|c|c|c|c|c|}
\hline & $\begin{array}{l}X^{2} \\
P \text {-value }\end{array}$ & RMSEA & $\mathrm{CFI}$ & $\overline{T L I}$ \\
\hline AM (autonomous motivation) & $\begin{array}{l}106.1 \\
0.052\end{array}$ & 0.05 & 0.96 & 0.94 \\
\hline CM (controlled motivation) & $\begin{array}{l}0.092 \\
0.95\end{array}$ & 0.05 & 0.95 & 0.93 \\
\hline Lifelong learning motivation & $\begin{array}{l}211 \\
0.00\end{array}$ & 0.06 & 0.92 & 0.82 \\
\hline Autonomy satisfaction & $\begin{array}{l}117.9 \\
0.075\end{array}$ & 0.05 & 0.96 & 0.94 \\
\hline Competence satisfaction & $\begin{array}{l}46.3 \\
0.102\end{array}$ & 0.03 & 0.95 & 0.92 \\
\hline Relatedness satisfaction & $\begin{array}{l}282.2 \\
0.006\end{array}$ & 0.04 & 0.98 & 0.89 \\
\hline
\end{tabular}




\section{Abbreviations}

AM: Autonomous motivation; CFI: Comparative fit index; CM: Controlled motivation; CPD: Continuing professional development; RMSEA: Root mean square error approximation; SDT: Self-determination Theory; TLI: Tucker-Lewis index

\section{Acknowledgements}

The authors would like to thank all medical specialists who participated in this study. We also like to thank Betsy van Soelen Director, and Joke Bais MD, from NWZ groep Alkmaar, Eric Sonneveld MD, and Pieter Kieviet MD, from Westfriesgasthuis Hoorn, Huub Cense MD, from Rode kruis ziekenhuis Beverwijk and Peter de Winter MD, and Arjen Noordzij MD, from Spaarne gasthuis Haarlem, for helping distribute the questionnaire among all medical specialists working in these hospitals.

\section{Authors' contributions}

All authors, SB, RK, JW, ST, GC and SP, were involved in the conceptualization of the study. SB carried out the logistical part of sending out the questionnaire. SB and JW analyzed the data and all authors (SB, RK, JW, ST, GC and SP) contributed to the interpretation of the results. SB drafted the manuscript and all authors contributed to critical revisions of the manuscript. All authors, SB, RK, JW, ST, GC and SP contributed to important intellectual content of the study and approved the final version of the manuscript.

\section{Funding}

This research received no specific grant from any funding agency in the public, commercial or not-for-profit sectors.

\section{Availability of data and materials}

The dataset generated and analyzed during the current study is available from the corresponding author on request.

\section{Ethics approval and consent to participate}

For this study, the Medical Ethics Review Committee of VU University Medical Center Amsterdam, the Netherlands, granted an exemption from ethics approval. To ensure compliance with the rules laid down by the Declaration of Helsinki, participants were told that their participation in the study was voluntary, there was a guarantee of confidentiality and anonymity, and that non-participation would not cause them any harm. Before participants could start the online questionnaire, they were informed about the research protocol and had to give their written informed consent.

\section{Consent for publication}

Not applicable.

\section{Competing interests}

The authors declare that they have no competing interests.

\section{Author details}

Amsterdam UMC, Vrije Universiteit Amsterdam, Research in Education, VUmc School of Medical Sciences, de Boelelaan 1117, Amsterdam, The Netherlands. ${ }^{2}$ Department of Epidemiology \& Biostatistics, VU University Medical Center Amsterdam, Amsterdam, The Netherlands. ${ }^{3}$ PAOFarmacie, The Netherlands Centre for Post-Academic Education in Pharmacy, Amsterdam, The Netherlands. ${ }^{4}$ Department of Neurosurgery, VU University Medical Center Amsterdam, Amsterdam, The Netherlands. ${ }^{5}$ LEARN! Research Institute for Learning and Education, Faculty of Psychology and Education, VU University Amsterdam, Amsterdam, The Netherlands.

Received: 5 March 2019 Accepted: 14 August 2019

\section{Published online: 05 September 2019}

\section{References}

1. Langelaan M, Broekens MA, de Bruijne MC, et al. Monitor Zorggerelateerde schade 2015/2016: Dossieronderzoek bij overleden patienten in Nederlandse ziekenhuizen. Available from: https://www.nivel.nl/sites/default/ files/bestanden/Rapport_Monitor_Zorggerelateerde_Schade_2017.pdf. Accessed Oct 2017.

2. WHO. World Health Report 2013. Available at: http://www.who.int/whr/2 013/main_messages/en/. Accessed 20 Nov 2013.
3. Van den Goor MMPG, Wagner CC, Lombarts KMJMH. Poor physicians performance in the Netherlands: characteristics, causes, and prevalence. J patient saf. 2015:505-1767.

4. Van Luijk SJ, Mook WNKA, Oosterhout WPJ. Het leren en toetsen van de professionele rol. Tijdschrift voor Medisch Onderwijs. 2009;28(3):107-18.

5. Choudhry NK, Fletcher RH, Soumerai SB. Systematic review: the relationship between clinical experience and quality of health care. Ann Intern Med. 2005;142:260-73.

6. Ikenwilo D, Skåtun D. Perceived need and barriers to continuing professional development among doctors. Health Policy. 2014;117:195-202.

7. Lowe MM, Aparicio A, Galbraith R, Dorman T, Dellert E. The future of continuing medical education: effectiveness of continuing medical education. Chest. 2009:135:69-75.

8. Tjin a tsoi SLN, de Boer A, Croiset G, Koster A, Kusurkar RA. Factors influencing participation in continuing professional development: a focus on motivation among pharmacists. J Contin Educ Health. 2016;36(3):144-50.

9. Lombarts KM, Plochg T, Thompson CA, Arah OA. Measuring professionalism in medicine and nursing: results of a European survey. PLoS One. 2014;9:e97069.

10. Roland M, Rao SR, Sibbald B, Hann M, Harrison S, Walter A, et al. Professional values and reported behaviours of doctors in the USA and UK: quantitative survey. BMJ Qual Saf. 2011;20:515-21.

11. Wenghofer Ef CC, Marlow B, Kam SM, Carter L, McCauley W. The effect of continuing professional development on public complaints: a case control study. Med Educ. 2015;49:264-75.

12. Gopee N. Human and social capital as facilitators of lifelong learning in nursing. Nurse Educ Today. 2002;22:608-16.

13. Deci EL, Ryan RM. Handbook of self-determination research. Rochester, NY: The university of Rochester Press; 2017.

14. Ryan RM, Deci EL. Intrinsic and extrinsic motivations: classic definitions and new directions. Contemp Educ Psychol. 2000;25:54-67.

15. Vallerand R. Deci and Ryan's self-determination theory: a view from the hierarchical model of intrinsic and extrinsic motivation. Psychol Inq. 2000;11:312-8.

16. Kusurkar RA, Croiset G, Galindo-Garré F, Ten Cate TJ. Motivational profiles of medical students: association with study effort, academic performance and exhaustion. BMC Med Educ. 2013;19:87.

17. Kusurkar RA, Ten Cate TJ, Vos CM, Westers P, Croiset G. How motivation affects academic performance: a structural equation modelling analysis. Adv Health Sci Educ Theor Pract. 2013;18:57-69.

18. Van der Burgt SME, Kusurkar RA, Wilschut JA, Tjin A, Tsoi SLNM, Croiset G, Peerdeman SM. Motivational profiles and motivation for lifelong learning of medical specialists. J Contin Educ Heal Prof. 2018;38(3):171-8.

19. Ryan RM, Deci EL. Self-determination theory and the facilitation of intrinsic motivation, social development, and well-being. Am Psychol. 2000;55(1):68-78

20. Deci EL, Ryan RM. Facilitating optimal motivation and psychological wellbeing across life's domains. Can Psychol/Psychol Can. 2008;49(1):14

21. Williams G. Improving health through supporting the autonomy of patients and providers. In: Handbook of self-determination research. Rochester, NY: University of Rochester Press; 2004. p. 233-54.

22. Beaton DE, Bombardier C, Guillemin F, Bosi Feraz M. Guidelines for the process of cross-cultural adaptation of self-report measures. Spine. 2000;25:3186-91.

23. Gagné $M$, Forest J, Vansteenkiste $M$, Crevier-Braud $L$, van den Broeck $A$, Aspeli AK, et al. The multidimensional work motivation scale: validation evidence in seven languages and nine countries. Eur J Work Organ Psychol. 2015;24:178-96

24. Hojat M, Veloski J, Nasca TJ, et al. Assessing physicians' orientation toward lifelong learning. J Gen Intern Med. 2006;21:931-6.

25. Vansteenkiste M, Ryan RM. On psychological growth and vulnerability: basic psychological need satisfaction and need frustration as a unifying principle. J Psychother Integr. 2013;23(3):263.

26. Anderson NR, West MA. Measuring climate for workgroup innovation: development and validation of the team climate inventory. J Organ Behav. 1998;19:235-58.

27. Devlieger I, Rosseel Y. Factor score path analysis: an alternative for SEM? Methodol. 2017:13:31-8.

28. Devlieger I, Mayer A, Rosseel Y. Hypothesis testing using factor score regression: a comparison of four methods. Educ Psychol Meas. 2016;76:741-70.

29. Croon M. In: Marcoulides GA, Moustaki I, editors. Latent variables and latent structure models Using predicted latent scores in general latent structure models. New York: Psychology Press; 2002. p. 195-224.

30. Kline RB. Principles and practice of structural equation modeling. 3rd ed. NY: The Guillford Press; 2011. 
31. Monitor for specialty choices in medical education Netherlands 2015. Available from: https://www.nivel.nl/sites/default/files/bestanden/ keuzemonitor_geneekunde_2015.pdf

32. Tjin A, Tsoi SLNM, de Boer A, Croiset G, Koster AS, Kusurkar RA. Unraveling motivational profiles of health care professionals for continuing education; the example of pharmacists in the Netherlands. J Cont Educ Health Prof. 2016;36(1):46-54

33. Williams GC, Freedman ZR, Deci EL. Supporting autonomy to motivate glucose control in patients with diabetes. Diabetes Care. 1998;21:1644-51.

34. Volkening U, Ostermann H, Link L, Hubner FW. The impact of selfdetermination on academic motivation of occupational therapists and physiotherapists in continuing higher education in Germany. J Contin High Educ. 2010;58:85-98.

35. Kusurkar RA, Croiset G. Ten Cate ThJ. Implications of gender differences in motivation among medical students. Med Teach. 2013;35(2):173-4.

36. Van der Burgt SME, Kusurkar RA, Croiset G, Peerdeman SM. Exploring the situational motivation of medical specialists: a qualitative study. Int J Med Educ. 2018;9:57-63.

37. Stajkovic AD, Luthans F. Business ethics across cultures: a social cognitive model. J World Bus. 1997;32(1):17-34.

\section{Publisher's Note}

Springer Nature remains neutral with regard to jurisdictional claims in published maps and institutional affiliations.

Ready to submit your research? Choose BMC and benefit from:

- fast, convenient online submission

- thorough peer review by experienced researchers in your field

- rapid publication on acceptance

- support for research data, including large and complex data types

- gold Open Access which fosters wider collaboration and increased citations

- maximum visibility for your research: over $100 \mathrm{M}$ website views per year

At BMC, research is always in progress.

Learn more biomedcentral.com/submissions 